\title{
COMU
}

\section{O Início do Congresso Médico Universitário}

\author{
Paulo Manuel Pêgo Fernandes
}

Historiador e Coordenador do Museu Histórico Prof. Carlos da Silva Lacaz da Faculdade de Medicina da Universidade de

INTRODUÇÃO

$E^{n}$ m 2012, o Congresso Médico Universitário da FMUSP - COMU - chega a sua trigésima primeira edição. Em sua última edição, contou com mais de 600 inscritos para os seus cursos, workshops e simpósio. Mais de 250 professores e palestrantes, além de 50 acadêmicos envolvidos na organização, também fizeram parte do XXX COMU.

Dentre os congressistas estavam representadas mais de vinte faculdades de medicina, e diversos acadêmicos de outras áreas da saúde. A importância do congresso em nível nacional ficou comprovada pela participação de acadêmicos do Distrito Federal, Rio de Janeiro, de Brasília, de Minas Gerais, de Rondônia, Espírito Santo, do Rio Grande do Sul, de São Paulo e do Mato Grosso do Sul. Do estado de São Paulo, participaram acadêmicos de diversos municípios, além da capital.

\section{PERSPECTIVA HISTÓRICA}

\section{Breve historia do nascimento do COMU}

Entrei na Faculdade em 1977 e iniciei trabalhos em cirurgia experimental em 1978. No final do segundo ano da Faculdade, apresentei um primeiro trabalho em um congresso médico-universitário. A partir daí, apresentei vários outros trabalhos em 1979. Em 1980, amadureceu a ideia de criar um congresso acadêmico em nossa faculdade. Conversei com a diretoria do DC e começamos a trabalhar na ideia. Por ser o primeiro e por sabermos que o sucesso do primeiro tenderia a perpetuar o evento, decidimos preparar por 2 anos. Discutimos a programação, local, negociamos com a Diretoria da Faculdade os anfiteatros e as aulas acabarem mais cedo naquela semana. Negociamos com laboratórios o patrocínio e fizemos uma grande rede de divulgação por cartazes, telefonemas, visitas as nossas salas de aula e a outras faculdades (não havia internet, nem computadores acessíveis naquele período).

O COMU surgiu na década de 80 da vontade de alguns alunos da faculdade de medicina da universidade de São Paulo de realizar um congresso dentro da própria universidade, como já acontecia em algumas outras faculdades de medicina do país. As dificuldades iniciais, como organização e financiamento, foram amenizadas com o auxílio do então diretor da Faculdade de Medicina Prof. Dr. Mário Ramos de Oliveira. O primeiro COMU aconteceu entre os dias 31 de maio e 5 de junho de 1982, e contou com 6 opções de cursos, palestras, uma mesa redonda e apresentação de trabalhos científicos, incluindo o prêmio Oswaldo Cruz.

Desde sua primeira edição, o COMU contou com excelente público. Neste primeiro congresso, foram mais de 500 participantes de todo o estado de São Paulo e outros, como Minas gerais, Rio de Janeiro, Paraná, Paraíba e Rio Grande do Sul. Em 2007, o congresso contou com cerca de 1200 participantes, sendo o maior $\mathrm{COMU}$ já realizado.

\section{Módulos}

Ao longo dos anos, o congresso tem se aperfeiçoado constantemente. No início, existiam

Formado pela Faculdade de Medicina da USP, em 1982. Atualmente é Professor Associado da USP, médico assistente do Instituto do Coração da FMUSP. 
poucos cursos organizados em módulos, mas apresentava grande número de palestras e mesas redondas sobre os mais diversos temas, discussão de casos e atividades culturais. Os workshops, que hoje são um dos grandes atrativos do COMU, surgiram em 1995, mas só se tornaram constantes em 2005, no XXIV COMU. Este formato é mantido nos dias atuais, contando com discussões integradas sobre as diversas especialidades e contando com profissionais de altíssimo gabarito em cada palestra.

\section{Desafios}

Também é importante ressaltar a participação dos alunos ao longo destes 31 anos. Não é fácil organizar um congresso médico. No entanto, a cada ano a organização do congresso médico universitário da FMUSP é mais profissional, e digna de qualquer outro congresso médico. Os trabalhos científicos apresentados pelos acadêmicos também é de alto nível e sempre enobrecem o COMU.

É com muita satisfação que escrevo este editorial, pois percebo que uma pequena iniciativa começada em 1982 transformou-se em uma instituição tradicional da Faculdade de Medicina da Universidade de São Paulo. Tive a oportunidade e a honra de ser o presidente do primeiro COMU. Lembro-me dos anseios, ansiedades, negociações que envolveram esse evento e do apoio do então diretor da FMUSP, Prof. Mario Ramos de Oliveira, seu primeiro Presidente de Honra. Com esse trabalho conseguimos viabilizar espaço, anfiteatros, teatro e carga horária, com readequação, durante a semana do Congresso, do que hoje é denominado currículo nuclear. Com esse apoio, com o trabalho incansável dos alunos da Comissão Organizadora, e com a viabilização de apoio financeiro de várias empresas, conseguimos nascer. Nessa primeira edição já utilizamos a Revista de Medicina, da qual também tive o prazer de fazer parte da Diretoria, para publicação dos resumos dos trabalhos apresentados e para a publicação na íntegra dos trabalhos premiados.

Estou muito feliz por fazer parte desta história e muito grato por todos aqueles que colaboraram com este grande congresso. Tenho certeza que muitos outros congressos médicos universitários da FMUSP estarão por vir, sempre com excelência de ensino, organização e espírito educativo. 